\title{
WATER LOSS REDUCTION IN WATER DISTRIBUTION NETWORKS. CASE STUDY
}

\author{
HOȚUPAN Anca a, MARE Roxana a, *, HĂDĂREAN Adriana a \\ ${ }^{a}$ Technical University of Cluj-Napoca, Building Services Faculty, Department of Building Services Engineering, 128-130, \\ 21 Decembrie 1989 Boulevard, 400604 Cluj-Napoca, Romania, e-mails: anca.hotupan@insta.utcluj.ro, \\ adriana.hadarean@insta.utcluj.ro
}

Received: 21.02.2019 / Accepted: 23.03.2019/ Revised: 25.04.2019 / Available online: 31.05.2019

DOI: 10.2478/jaes-2019-0009

KEY WORDS: potable water distribution network, flow, pressure, real losses, infrastructure leakage, water management.

\begin{abstract}
:
Water losses on the potable water distribution networks represent an important issue; on the one hand, water loss does not bring money and on the other hand, they modify water flow and pressure distribution on the entire system and this can lead to a cut-off of the water supply. A stringent monitoring of the water distribution network reduces considerably the water losses. The appearance of a leakage inside the distribution network is inevitable in time. But very important is its location and repair time - that are recommended to be as short as possible. The present paper analyses the hydraulic parameters of the water flow inside a supply pipe of a looped network that provides potable water for an entire neighbourhood. The main goals are to optimize these parameters, to reduce water losses by rigorous monitoring and control of the service pressure on the supply pipe and to create a balance between pressure and water flow. The presented method is valid for any type of distribution network, but the obtained values refer strictly to the analysed potable water distribution looped network.
\end{abstract}

\section{INTRODUCTION}

Potable water distribution networks involve a great volume of multidisciplinary knowledge in all stages: design, execution and service. Moreover, every stage requires a special and significant attention of the hydraulic analysis and operation. Therefore, the hydraulic dimensioning of the looped network is the most important task in the design stage, while network water losses control, management and understanding are the most significant during the service time.

Water resource availability is the main issue on the international agenda. Potable water resources are in continuous decrease on both national and global level; furthermore, the real risk of pollution is increasing every day. Because of these, it is mandatory to elaborate and implement a water losses control system in all water distribution networks.

Network water losses prediction, control and/or reduction represent another "black box" in developing countries like Romania as in countries with a well-developed infrastructure and good operating practices.

The easiest way to verify and determine the existence of water losses in a potable water distribution network is to compare the values of the water flows measured in different points of interest of the network by means of water meters. These differences on water flow can have multiple causes: (i) an old infrastructure prone to accidents or cracks, (ii) the use of water meters with weak accuracy, (iii) human error in collecting, etc. Overall, the main goal is to realize a water balance on a section of the water network or on the entire potable water distribution network.

To achieve this water balance, a series of leakage performance indicators (EPA 2010) can be used to quantify and compare water losses from a distribution network. According to the United States Environmental Protection Agency, two important aspects are to be considered when establishing the real leakage performance indicators: Revenue Water (RW) and NonRevenue Water (NRW). While the RW consists of the billed metered and un-metered consumption, the NRW considers the total losses that appear or can appear in a transmission and distribution water system - unbilled authorized consumption, apparent losses and real losses. Practically, the NRW indicator represents the difference between the inlet and the outlet water flows.

A debate referring to the leakage performance indicators and the determination of a standard water balance still exists nowadays (Mckenzie, 2005, Farley and Trow, 2003). Leaving aside the unbilled authorized consumption, the International Water Association considers that the NRW equals with the water loss that appear in the network:

\footnotetext{
* Corresponding author: Roxana Mare, e-mail: roxana.mare@insta.utcluj.ro
} 
Water loss $=$ real losses + apparent losses

The apparent water losses are given by unauthorized consumption, human error in collecting data, meters inaccuracy, lack of flow meters in potable water distribution networks.

Real losses represent the physical losses that can appear in water storage systems (i.e. tanks overflows), in water distribution pipes, in pipe branches, respectively. In fact, the real losses are the water losses that can be physically determined between two measurement points as a result of leakage from pipes, joints and fittings. Considering the materials and data owned by the authors and all the aspects presented so far, the real losses and their reduction possibility represent the subject of the present paper.

Thus, the real losses are the same with the real water volume lost, which depends on the hydraulic parameters of the pipe network, the leak detection and the repair policy, as follows (Farley and Trow, 2003):

- the pressure in network;

- the frequency and typical flow rates of new leaks and burst;

- the proportions of new "reported" leaks;

- the "awareness" time (how quickly the loss is noticed);

- the "location" time (how quickly is located the new leak);

- the repair time (how quickly it is repaired or shut off);

- the level of "background" leakage (undetectable small leaks).

The authors of this paper will present mainly the analysis of the hydraulic parameters together with the estimated repair time according to the water flow. The aim of the analysis is to optimize the operation of the entire potable water distribution network as regarding the overpressure protection of the water network (Gomes, 2011) and water real losses too, by offering viable solutions. These are possible with the help of the so called method - pressure management (that will be detailed further on this paper).

This study analyses the case of a looped distribution network that provide the potable water for an entire neighbourhood in a big city. The main advantage of the looped network is the continuous supply of the water toward the consumers from two directions. So, if a leakage appears somewhere in the network the consumers will not be affected (the leakage modifies only the distribution of water flows and pressure) (Georgescu, 2007). This aspect cannot be stated for the water supply pipe; in this case a major problem occurs.

The leakage will have an important impact on both consumers: one of the water looped network and the others of the water downstream network; in other words, the leakage will affect the entire downstream water system.

Moreover, the variation of the water flow parameters along a looped network is hard to control and its rigorous monitoring implies a significant financial effort; due to this reason, the present paper will consider only the monitoring of the water supply pipe of the looped network.

The intention is to use a simple and efficient water loss reduction method in water distribution networks. This method can also be defined as the practice of managing water system pressure to achieve optimum levels of service, ensuring sufficient and efficient water supply flows to consumers (Thornton, Lambert, 2005).

\section{MATERIALS AND METHOD}

\subsection{Experimental data}

The case study from this paper presents the water pressure variation and the flow rate dependency. The entire study is based on data monitoring of a potable water supply system which implies a supply pipe and a loop network.

The looped network is made off three different types of pipes materials - steel, cement-asbestos and polyethylene, series and parallel connected, with various lengths and diameters.

The real water losses determined from water balance (Mckenzie, Seago, 2005) were registered for a period of two years, from January 2016 to December 2017. Comparing to the water volume expressed in $\mathrm{m}^{3}$, the water losses are presented as percentages and their values are between $25-47 \%$, as it can be seen in table 1 .

Table 1. Flowmeter water volumes and water real losses

\begin{tabular}{|c|c|c|c|c|c|}
\hline \multirow{2}{*}{ No. } & \multirow{2}{*}{ Month } & \multicolumn{2}{|c|}{$\begin{array}{l}\text { Water volume, } \\
\qquad\left(\mathrm{m}^{3}\right)\end{array}$} & \multicolumn{2}{|c|}{$\begin{array}{c}\text { Water-loss, } \\
{[\%]}\end{array}$} \\
\hline & & 2016 & 2017 & 2016 & 2017 \\
\hline 1 & January & 128581 & 128064 & 33.68 & 33.81 \\
\hline 2 & February & 140391 & 114767 & 38.89 & 32.68 \\
\hline 3 & March & 161922 & 125471 & 46.41 & 34.90 \\
\hline 4 & April & 136831 & 121944 & 39.83 & 31.93 \\
\hline 5 & May & 134230 & 128825 & 38.30 & 36.54 \\
\hline 6 & June & 123299 & 129437 & 30.99 & 32.00 \\
\hline 7 & July & 124546 & 130633 & 35.51 & 33.76 \\
\hline 8 & August & 129844 & 130463 & 35.25 & 32.34 \\
\hline 9 & September & 118010 & 128327 & 31.54 & 35.55 \\
\hline 10 & October & 108718 & 140148 & 23.65 & 41.93 \\
\hline 11 & November & 124073 & 130655 & 35.95 & 35.39 \\
\hline 12 & December & 118437 & 135521 & 30.25 & 37.91 \\
\hline
\end{tabular}

According to figure 1, the main characteristics of the water supply pipe of the looped network are known: the steel pipe's length is $14 \mathrm{~m}$ and the diameter is of $300 \mathrm{~mm}$, respectively. Because the pressure varies with the water flow, a flowmeter was mounted on the supply pipe to register all network incoming water volumes.

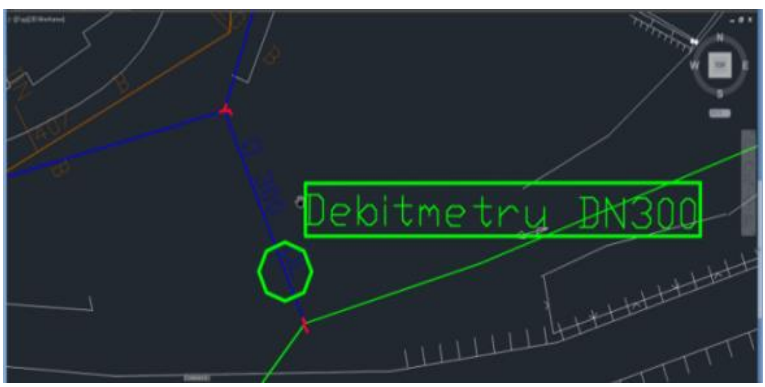

Figure 1. Supply pipe of the potable water distribution network 
By analysing the data from table 1 , one can easily see that for 2016, the maximum network incoming water volume (the one represented in blue colour in table 1) corresponds to March, while the minimum water volume is registered in October (represented with red in table 1).

For 2017, the situation is reversed. The maximum value of the incoming water volume is achieved in autumn, preciously in October when the minimum value was achieved for the last year. The minimum water volume is registered in winter, in February - but the value is still higher than the minimum one for 2016.

By comparing the water volumes and water losses from table 1 , a significant and tight correspondence between them is developed. Thus, the two parameters are directly proportional: the maximum water real loss corresponds to the month when the maximum water volume registered, while the minimum water real loss value occurred in the same month as the minimum water volume encountered.

\subsection{Relationship between the pressure drop and the flow rate in a pipeline}

The total energy or the water load of a section (Lazar, Muste, 1993) is given by relation:

$$
\mathrm{H}=\mathrm{z}+\frac{\mathrm{p}}{\gamma}+\frac{\alpha \cdot \mathrm{V}^{2}}{2 \cdot \mathrm{g}}
$$

where: $\quad \mathrm{z}$ represents the elevation of the pipe section, $[\mathrm{m}]$;

$$
\text { p- pressure, }\left[\mathrm{N} / \mathrm{m}^{2}\right] \text {; }
$$

$\gamma$ - the ratio of the specific heats, $\left[\mathrm{N} / \mathrm{m}^{3}\right]$;

$\mathrm{V}$ - average velocity across the pipe section, $[\mathrm{m} / \mathrm{s}]$

$\alpha=1$ - Coriolis coefficient, dimensionless;

g - gravitational acceleration, $\left[\mathrm{m} / \mathrm{s}^{2}\right]$.

From the continuity equation results the expression of velocity:

$$
\mathrm{V}=\frac{4 \cdot \mathrm{Q}}{\pi \cdot \mathrm{D}^{2}}
$$

where D represents the internal diameter of the supply pipe, $[\mathrm{m}]$ and $Q$ is the water flow, $\left[\mathrm{m}^{3} / \mathrm{s}\right]$.

By replacing the velocity in equation (1) we obtain:

$$
\mathrm{H}=\mathrm{z}+\frac{\mathrm{p}}{\gamma}+\frac{\alpha \cdot 16 \cdot \mathrm{Q}^{2}}{2 \cdot \mathrm{g} \cdot \pi^{2} \cdot \mathrm{D}^{4}}
$$

Because the water load is constant in a section, based on relation (3), the dependence between the pressure drop and the flow rate results. This means that when the minimum consumption is registered, the pressure will increase. Therefore, the maximum pressure will be determined with the help of the minimum flow rate, while the minimum pressure value is based on the maximum value of the water flow rate registered in the supply pipe. Namely, the pressure drop and flow rate are indirectly proportional. Hence, further analysis of the two hydraulic parameters will be presented considering the flow rates from March and October for 2016 and October and February for 2017, respectively (according to table 1).
An important aspect to be mentioned is the fluctuation of the water daily flow rate and due to this, the average values of the flow volumes from table 1 will be considered during the analysis.

\subsection{Linear friction losses along the supply pipe}

During the exploitation time, linear losses can appear along the supply pipe because of the friction between the pipe and water. Figure 2 emphasis the main supply pipe of the distribution looped network that delivers water for another two pipes oriented in two separate directions.

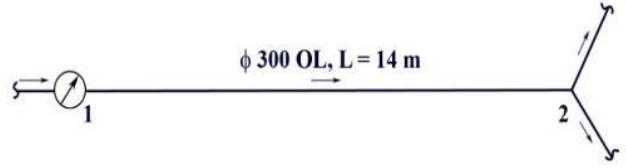

Figure 2. Characteristics of the main water supply pipe

The supply pipe presents two sections: section 1 which corresponds to the point where the flowmeter was mounted and section 2 - the final section of the supply pipe that coincide with the looped network junction (see also figure 1). Only the part of the supply pipe, between the two sections will be considered for the determination of the pressure drop.

The dependence of the two parameters - pressure and flow rate results from Bernoulli equation applied for sections 1 and 2:

$$
\mathrm{z}_{1}+\frac{\mathrm{p}_{1}}{\gamma}+\frac{\alpha_{1} \cdot \mathrm{V}_{1}^{2}}{2 \cdot \mathrm{g}}=\mathrm{z}_{2}+\frac{\mathrm{p}_{2}}{\gamma}+\frac{\alpha_{2} \cdot \mathrm{V}_{2}^{2}}{2 \cdot \mathrm{g}}+\mathrm{h}_{12}
$$

where $\mathrm{z}$ - geodesic level of the two nodes, [m].

$\mathrm{p}$ - pressure in sections 1 and $2,\left[\mathrm{~N} / \mathrm{m}^{2}\right]$;

$\mathrm{V}$ - average velocity in section 1 and $2,[\mathrm{~m} / \mathrm{s}]$.

$\alpha_{1}=\alpha_{2}=1$-Coriolis Coefficient

$\mathrm{h}_{12}-$ linear friction losses on the supply pipe $1-2,[\mathrm{~m}]$, that is calculated with the following formula:

$$
\mathrm{h}_{12}=0.0826 \cdot \frac{\lambda \cdot \mathrm{L}}{\mathrm{D}^{5}} \cdot \mathrm{Q}^{2}
$$

where $\lambda$ is the Darcy friction factor, dimensionless, while $\mathrm{L}$ represents the $1-2$ pipe length, $L=14 \mathrm{~m}$.

From the continuity equation:

$$
\mathrm{Q}=\mathrm{V} \cdot \frac{\pi \cdot \mathrm{D}^{2}}{4}
$$

in which the water flow $\mathrm{Q}=$ constant, the pipe diameter $\mathrm{D}$ is constant, too, results that the velocity $\mathrm{V}$ is also constant. This leads to a parity of the two velocities in sections 1 and 2 and by default to the reduction of the kinetic parameters in Bernoulli's equation. Therefore, relation (4) becomes:

$$
=>\frac{\mathrm{p}_{2}}{\gamma}=\frac{\mathrm{p}_{1}}{\gamma}+\mathrm{z}_{1}-\mathrm{z}_{2}-0.0826 \cdot \frac{\lambda \cdot \mathrm{L}}{\mathrm{D}^{5}} \cdot \mathrm{Q}^{2}
$$

In the hypothesis of a straight and horizontal supply pipe, $\mathrm{z}_{1}=\mathrm{z}_{2}$ and equation (7) becomes:

$$
=>\frac{\mathrm{p}_{2}}{\gamma}=\frac{\mathrm{p}_{1}}{\gamma}-0.0826 \cdot \frac{\lambda \cdot \mathrm{L}}{\mathrm{D}^{5}} \cdot \mathrm{Q}^{2}
$$


The velocity values where determined with the next formula:

$$
\mathrm{V}=\frac{4 \cdot \mathrm{Q}_{\mathrm{med}, \mathrm{h}}}{\pi \cdot \mathrm{D}^{2}}, \quad[\mathrm{~m} / \mathrm{s}]
$$

The Darcy friction factor $\lambda$ was determined on pipe 1-2 according to the following steps:

$>$ the establishment of the flow regime according to Reynolds criteria:

$$
\operatorname{Re}=\frac{\mathrm{V} \cdot \mathrm{D}}{v},
$$

where $\gamma$ - kinematic viscosity of the fluid, $\left[\mathrm{m}^{2} / \mathrm{s}\right]$,

$v=1.31 \cdot 10^{-6} \mathrm{~m}^{2} / \mathrm{s}$,

the other parameters have been previously explained.

$>$ the Darcy friction factor $\lambda$ was calculated according to the flow regime type as follows:

* Smooth turbulent flow - Konakov formula, (L. Marian):

$$
\lambda=\frac{1}{(1.8 \cdot \lg (\mathrm{Re})-1.5)^{2}}
$$

* Semi-rough turbulent flow - Chen formula, (F. Salmasi):

$$
\lambda=\left\{-2 \cdot \lg \left[\frac{\mathrm{k} / \mathrm{D}}{3.7065}-\frac{5.0452}{\mathrm{Re}} \cdot \lg \left(\frac{(\mathrm{k} / \mathrm{D})^{1.1098}}{2.8257}+\frac{5.8506}{\mathrm{Re}^{0.8981}}\right)\right]\right\}^{-2}
$$

* Rough turbulent flow - Prandtl-Nicuradse formula, (L. Marian):

$$
\frac{1}{\sqrt{\lambda}}=1.14-2 \cdot \lg \left(\frac{\mathrm{k}}{\mathrm{D}}\right)
$$

in which:

$\mathrm{k} / \mathrm{D}$ - relative roughness of the pipe,

$$
\mathrm{k}=0.045 \mathrm{~mm} \text {, (NP 133-2013), }
$$$$
\mathrm{D}=300 \mathrm{~mm} \text {. }
$$

While the water flow rates are being known due to the existence of the flowmeter at the beginning of the supply pipe, the water pressures are not known and that is why, the calculation and the analysis are conducted on the hypothesis that the input pressure is 4.7 bar $(47 \mathrm{mCA})$. The output pressure values are presented in tables 2 and 3 according to the methodology presented before.

The results from tables 2 and 3 emphasis a very small variation

\begin{tabular}{|c|c|c|c|c|c|c|c|c|c|c|}
\hline \multirow{2}{*}{ Hour } & \multicolumn{2}{|c|}{$\mathrm{V}[\mathrm{m} / \mathrm{s}]$} & \multicolumn{2}{|c|}{$\operatorname{Re}$} & \multicolumn{2}{|c|}{$\lambda$} & \multicolumn{2}{|c|}{$\mathrm{h}_{\mathrm{d}}[\mathrm{m}]$} & \multicolumn{2}{|c|}{$\mathrm{p}_{2}[\mathrm{mCA}]$} \\
\hline & 2016 & 2017 & 2016 & 2017 & 2016 & 2017 & 2016 & 2017 & 2016 & 2017 \\
\hline $0 \ldots 1$ & 0.53 & 0.48 & 122279.26 & 109300.09 & 0.0171 & 0.0175 & 0.0116 & 0.0095 & 46.98865 & 46.99072 \\
\hline $1 \ldots 2$ & 0.49 & 0.44 & 112873.16 & 00892.39 & 0.0173 & 0.0177 & 0.0100 & 0.0082 & 46.99017 & 46.99196 \\
\hline $2 \ldots 3$ & 0.45 & 0.40 & 103467.07 & 92484.69 & 0.0177 & 0.0181 & 0.0086 & 0.0070 & 46.99159 & 46.99312 \\
\hline $3 \ldots 4$ & 0.43 & 0.39 & 98764.02 & 88280.84 & 0.0178 & 0.0182 & 0.0079 & 0.0065 & 46.99226 & 46.99367 \\
\hline $4 \ldots .5$ & 0.45 & 0.40 & 103467.07 & 92484.69 & 0.0177 & 0.0181 & 0.0086 & 0.0070 & 46.99159 & 46.99312 \\
\hline $5 \ldots 6$ & 0.86 & 0.77 & 197528.04 & 176561.68 & 0.0155 & 0.0158 & 0.0274 & 0.0224 & 46.97309 & 46.97802 \\
\hline $6 \ldots 7$ & 1.09 & 0.97 & 249261.57 & 222804.03 & 0.0187 & 0.0191 & 0.0526 & 0.0429 & 46.9484 & 46.9579 \\
\hline $7 \ldots 8$ & 1.17 & 1.05 & 268073.76 & 239619.42 & 0.0184 & 0.0188 & 0.0600 & 0.0490 & 46.94111 & 46.95197 \\
\hline $8 \ldots 9$ & 1.15 & 1.03 & 263370.72 & 235415.57 & 0.0185 & 0.0189 & 0.0581 & 0.0474 & 46.94298 & 46.95349 \\
\hline $9 \ldots 10$ & 1.11 & 0.99 & 253964.62 & 227007.88 & 0.0186 & 0.0190 & 0.0544 & 0.0444 & 46.94662 & 46.95645 \\
\hline $10 \ldots 11$ & 1.09 & 0.97 & 249261.57 & 222804.03 & 0.0187 & 0.0191 & 0.0526 & 0.0429 & 46.9484 & 46.9579 \\
\hline $11 \ldots 12$ & 1.09 & 0.97 & 249261.57 & 222804.03 & 0.0187 & 0.0191 & 0.0526 & 0.0429 & 46.9484 & 46.9579 \\
\hline $12 \ldots 13$ & 1.07 & 0.95 & 244558.52 & 218600.18 & 0.0187 & 0.0191 & 0.0508 & 0.0415 & 46.95016 & 46.95933 \\
\hline $13 \ldots 14$ & 1.05 & 0.94 & 239855.47 & 214396.33 & 0.0188 & 0.0192 & 0.0490 & 0.0400 & 46.95188 & 46.96073 \\
\hline $14 \ldots .15$ & 1.01 & 0.90 & 230449.38 & 205988.63 & 0.0189 & 0.0193 & 0.0456 & 0.0372 & 46.95525 & 46.96347 \\
\hline $15 \ldots 16$ & 0.92 & 0.83 & 211637.18 & 189173.23 & 0.0192 & 0.0197 & 0.0391 & 0.0319 & 46.96164 & 46.96867 \\
\hline $16 \ldots 17$ & 0.86 & 0.77 & 197528.04 & 176561.68 & 0.0195 & 0.0199 & 0.0345 & 0.0282 & 46.96614 & 46.97233 \\
\hline $17 \ldots 18$ & 0.97 & 0.86 & 221043.28 & 197580.93 & 0.0191 & 0.0195 & 0.0423 & 0.0345 & 46.9585 & 46.96612 \\
\hline $18 \ldots 19$ & 1.03 & 0.92 & 235152.43 & 210192.48 & 0.0189 & 0.0193 & 0.0473 & 0.0386 & 46.95358 & 46.96211 \\
\hline $19 \ldots 20$ & 1.03 & 0.92 & 235152.43 & 210192.48 & 0.0189 & 0.0193 & 0.0473 & 0.0386 & 46.95358 & 46.96211 \\
\hline $20 \ldots 21$ & 0.86 & 0.77 & 197528.04 & 176561.68 & 0.0155 & 0.0158 & 0.0274 & 0.0224 & 46.97309 & 46.97802 \\
\hline $21 \ldots 22$ & 0.68 & 0.61 & 155200.60 & 138727.03 & 0.0163 & 0.0166 & 0.0178 & 0.0145 & 46.98258 & 46.98577 \\
\hline $22 \ldots .23$ & 0.60 & 0.53 & 136388.41 & 121911.64 & 0.0167 & 0.0171 & 0.0141 & 0.0115 & 46.98619 & 46.98872 \\
\hline $23 \ldots 24$ & 0.55 & 0.50 & 126982.31 & 113503.94 & 0.0169 & 0.0173 & 0.0124 & 0.0101 & 46.98786 & 46.99007 \\
\hline
\end{tabular}
of the pressure in section 2 that equals to very small linear friction losses along the supply pipe. In consequence, a constant supply pressure $\mathrm{p}_{1}$ leads to an approximate constant pressure along the supply pipe of the looped network.

Table 2. Hydraulic parameters for the maximum flow 
Table 3. Hydraulic parameters for the minimum flow

\begin{tabular}{|c|c|c|c|c|c|c|c|c|c|c|}
\hline \multirow[t]{2}{*}{ Hour } & \multicolumn{2}{|c|}{$\begin{array}{c}\mathrm{V} \\
{[\mathrm{m} / \mathrm{s}]}\end{array}$} & \multicolumn{2}{|c|}{$\mathrm{Re}$} & \multicolumn{2}{|c|}{$\lambda$} & \multicolumn{2}{|c|}{$\begin{array}{l}\mathrm{h}_{\mathrm{d}} \\
{[\mathrm{m}]}\end{array}$} & \multicolumn{2}{|c|}{$\begin{array}{c}\mathrm{p}_{2} \\
{[\mathrm{mCA}]}\end{array}$} \\
\hline & 2016 & 2017 & 2016 & 2017 & 2016 & 2017 & 2016 & 2017 & 2016 & 2017 \\
\hline $0 \ldots 1$ & 0.36 & 0.42 & 82100.99 & 95955.01 & 0.0185 & $\begin{array}{ll}0.0179 \\
\end{array}$ & 0.0057 & 0.0075 & " 46.99444 & 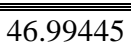 \\
\hline $1 \ldots 2$ & 0.33 & 0.39 & 75785.53 & 88573.85 & 0.0189 & 0.0182 & 0.0049 & 0.0065 & 46.99518 & 46.99519 \\
\hline $2 \ldots 3$ & 0.30 & 0.35 & 69470.07 & 81192.70 & 0.0192 & 0.0186 & 0.0042 & 0.0055 & 46.99588 & 46.99588 \\
\hline $3 . . .4$ & 0.29 & 0.34 & 66312.34 & 77502.12 & 0.0194 & 0.0188 & 0.0039 & 0.0051 & 46.9962 & 46.99621 \\
\hline $4 \ldots 5$ & 0.30 & 0.35 & 69470.07 & 81192.70 & 0.0192 & 0.0186 & 0.0042 & 0.0055 & 46.99588 & 46.99588 \\
\hline $5 \ldots 6$ & 0.58 & 0.68 & 132624.68 & 155004.24 & 0.0168 & 0.01 & 0.0134 & 0.0177 & 46.98687 & 46.98689 \\
\hline $6 \ldots 7$ & 0.73 & 0.85 & \begin{tabular}{|l|}
167359.71 \\
\end{tabular} & 195600.59 & 0.0202 & 0.0195 & 0.0256 & 0.0339 & 46.97487 & 46.97491 \\
\hline $7 \ldots 8$ & 0.79 & 0.92 & \begin{tabular}{|l}
179990.63 \\
\end{tabular} & 210362.90 & 0.0199 & 0.0193 & 0.0292 & 0.0386 & 46.97136 & 46.9714 \\
\hline $8 \ldots 9$ & 0.77 & 0.90 & \begin{tabular}{|l}
176832.90 \\
\end{tabular} & 206672.32 & 0.0199 & 0.0193 & 0.0283 & 0.0374 & 46.97226 & 46.97229 \\
\hline $9 \ldots 10$ & 0.74 & 0.87 & 170517.44 & 199291.17 & 0.0201 & 0.0195 & 0.0265 & 0.0350 & 46.97401 & 46.97405 \\
\hline $10 \ldots 11$ & 0.73 & 0.85 & 167359.71 & 195600.59 & 0.0202 & 0.0195 & 0.0256 & 0.0339 & 46.97487 & 46.97491 \\
\hline $11 \ldots 12$ & 0.73 & 0.85 & \begin{tabular}{|l|}
167359.71 \\
\end{tabular} & 195600.59 & 0.0202 & 0.0195 & 0.0256 & 0.0339 & 46.97487 & 46.97491 \\
\hline $12 \ldots 13$ & 0.72 & 0.84 & 164201.98 & 191910.01 & 0.0202 & 0.0196 & 0.0248 & 0.0327 & 46.97572 & 46.97575 \\
\hline $13 \ldots 14$ & 0.70 & 0.82 & 161044.25 & & 0.0203 & & 0.0239 & 0.0316 & 46.97655 & 46.97658 \\
\hline $14 \ldots .15$ & 0.68 & 0.79 & 154728.79 & 180838.28 & 0.0205 & 0.0199 & 0.0223 & 0.0294 & 46.97817 & 46.9782 \\
\hline $15 \ldots 16$ & 0.62 & 0.73 & 142097.87 & 166075.97 & 0.0209 & 0.0202 & 0.0191 & 0.0252 & 46.98126 & 46.98128 \\
\hline $16 \ldots 17$ & 0.58 & 0.68 & \begin{tabular}{|l|}
132624.68 \\
\end{tabular} & 155004.24 & 0.0212 & 0.0205 & 0.0169 & 0.0223 & 46.98343 & 46.98346 \\
\hline $17 \ldots 18$ & 0.65 & 0.76 & 148413.33 & 173457.13 & 0.0207 & 0.0200 & 0.0206 & 0.0273 & 46.97974 & 46.97977 \\
\hline $18 \ldots 19$ & 0.69 & 0.81 & 157886.52 & 184528.86 & 0.0204 & 0.0198 & 0.0231 & 0.0305 & 46.97737 & 46.9774 \\
\hline $19 \ldots 20$ & 0.69 & 0.81 & 157886.52 & 184528.86 & 0.0204 & 0.0198 & 0.0231 & 0.0305 & 46.97737 & 46.9774 \\
\hline $20 \ldots 21$ & 0.58 & 0.68 & 132624.68 & 155004.24 & 0.0168 & 0.0163 & 0.0134 & 0.0177 & 46.98687 & 46.98689 \\
\hline $21 \ldots 22$ & 0.46 & 0.53 & 104205.10 & 121789.05 & 0.0176 & 0.0171 & 0.0087 & 0.0115 & 46.99148 & 46.9915 \\
\hline $22 \ldots 23$ & 0.40 & 0.47 & \begin{tabular}{|l|l|}
91574.18 \\
\end{tabular} & 107026.74 & 0.0181 & 0.0175 & 0.0069 & 0.0091 & 46.99324 & 46.99325 \\
\hline $23 \ldots 24$ & 0.37 & 0.44 & 85258.72 & 99645.58 & 0.0184 & 0.0178 & 0.0061 & 0.0080 & 46.99405 & 46.99406 \\
\hline
\end{tabular}

\subsection{Water loss variation}

Water losses exist in every potable water distribution network. But it is desired that these losses - apparent and real - to be as small as possible. Leaving aside the apparent losses, the paper will focus, as it did until now, on the real water losses.

The amount of water losses depend on the system pressure regime; also, water losses influences and modifies the system pressure and flow. Probably a leakage will appear in the looped network especially at night when the flow registers the minimum value, while the pressure the maximum ones (according to relation (3)). This is a consequence of the higher pressure upon the pipes which are not at their maximum resistance during the exploitation time. The highest, frequent and repeated stresses caused by high pressure conduct to the weakening of the pipes wall and implicit, to the appearance of leakages. When the leakage occurs in the pipe wall, the pressure sharply drops.

Leakage pressure value depends on several factors: (i) the dimension and shape of the hole from the pipe wall, (ii) the diameter and the thickness of the pipe, (iii) the pipe material, (iv) the optimum pressure and flow.

The entire leakage phenomenon is very complex, reason why mathematical modelling is difficult; in most cases, the leakage pressure is experimentally determined.

The variation of the leakage parameters can be studied only by supposing a leakage on the supply pipe (otherwise, on the looped network is too complex).
The water loss will be calculated by applying the relation of the flow through holes (van Zyl, 2014, Lambert, 2000) and it is referring only to the real losses that are an important part of the Non Revenue Water:

$$
Q_{N R W}=C_{d} \cdot a \cdot \sqrt{2 \cdot g} \cdot p_{h}^{N_{1}}, \quad\left[m^{3} / s\right] ;
$$

where: $\quad C_{d}-$ coefficient of discharge $\mathrm{Cd}, \mathrm{C}_{d}=0.8$;

a - hole surface, $\left[\mathrm{m}^{2}\right]$, the hole is considered circular, $\mathrm{a}=\left(\pi \cdot \mathrm{d}^{2}\right) / 4$;

$$
\begin{aligned}
& \mathrm{d} \text { - hole diameter, }[\mathrm{m}] \\
& \mathrm{g}-\text { gravitational acceleration, } \mathrm{g}=9.81 \mathrm{~m} / \mathrm{s}^{2} \text {; }
\end{aligned}
$$

$\mathrm{P}_{\mathrm{h}}$ - hole pressure, [mCA];

$\mathrm{N}_{1}$ - exponent that varies between 0.5 and 2.5 ,

(Nourhan, 2017). The exponent value is influenced by the hole shape, thickness of the pipe wall, its elastic ratio and flow regime (De Paola and Giugni, 2012). The value of $\mathrm{N}_{1}=0.5$ for rigid pipe walls and turbulent flow recommended by (Thornton, Lambert, 2005), (Gomes, 2013) is adopted in this case study, too.

By using relation (14), water losses were calculated in $1 / \mathrm{h}$ for different hole diameter values on the supply pipe wall (d) and hole pressure values, respectively. The results are presented in table 4 . The obtained water losses were further verified with the formula given by (Tabesh, 2009):

$$
Q_{N R W}=5.042 \cdot C_{d} \cdot a \cdot p_{h}^{0.5} \quad[l / h]
$$

where: $\quad \mathrm{Q}_{\mathrm{NRW}}$ - water loss; 
$\mathrm{C}_{\mathrm{d}}$ - coefficient of discharge $\mathrm{Cd}, \mathrm{C}_{\mathrm{d}}=0.8$;

a - hole surface, $\mathrm{a}=\left(\pi \cdot \mathrm{d}^{2}\right) / 4, \quad\left[\mathrm{~cm}^{2}\right]$;

$\mathrm{P}_{\mathrm{h}}-$ pressure, atm.

Table 4 . Water losses in $1 / \mathrm{h}$ depending on the hole diameter and pressure

\begin{tabular}{|c|c|c|c|c|c|c|c|c|c|c|}
\hline & \multicolumn{10}{|c|}{$\mathrm{Ph}_{\mathrm{h}}[\mathrm{mCA}]$} \\
\hline $\mathrm{d}[\mathrm{mm}]$ & 39 & 38 & 37 & 36 & 35 & 34 & 33 & 32 & 31 & 30 \\
\hline 2 & 61.28 & 60.38 & 59.46 & 58.54 & 57.60 & 56.65 & 55.69 & 54.72 & 53.73 & 52.73 \\
\hline 4 & 245.14 & 241.52 & 237.86 & 234.15 & 230.40 & 226.61 & 222.76 & 218.87 & 214.92 & 210.92 \\
\hline 6 & 551.56 & 543.41 & 535.17 & 526.84 & 518.40 & 509.86 & 501.21 & 492.45 & 483.58 & 474.58 \\
\hline 8 & 980.56 & 966.07 & 951.42 & 936.60 & 921.60 & 906.42 & 891.05 & 875.48 & 859.69 & 843.69 \\
\hline 10 & 1532.12 & 1509.49 & 1486.59 & 1463.44 & 1440.00 & 1416.28 & 1392.26 & 1367.93 & 1343.27 & 1318.27 \\
\hline 12 & 2206.25 & 2173.66 & 2140.70 & 2107.35 & 2073.61 & 2039.45 & 2004.86 & 1969.82 & 1934.31 & 1898.30 \\
\hline 14 & 3002.96 & 2958.59 & 2913.73 & 2868.34 & 2822.41 & 2775.92 & 2728.84 & 2681.14 & 2632.81 & 2583.80 \\
\hline 16 & 3922.23 & 3864.28 & 3805.68 & 3746.40 & 3686.41 & 3625.69 & 3564.19 & 3501.90 & 3438.77 & 3374.76 \\
\hline 18 & 4964.07 & 4890.73 & 4816.57 & 4741.54 & 4665.62 & 4588.76 & 4510.93 & 4432.09 & 4352.19 & 4271.19 \\
\hline 20 & 6128.48 & 6037.94 & 5946.38 & 5853.75 & 5760.02 & 5665.14 & 5569.05 & 5471.72 & 5373.08 & 5273.07 \\
\hline
\end{tabular}

The water losses values calculated with relation (14) and verified with equation (15) were identically. Therefore, their values are presented once, in table 4 .

According to Karadirek (2012) and the physical phenomenon that occurs during a leakage on the water supply pipe of a looped network, the pressure system will drop dramatically. Unfortunately, no pressure gauge was mounted on the supply pipe of the looped network. The only pressure values that we have are the values measured closed to the beginning of the supply pipe. This is the reason why the registered values of 4.0 bar ( $40 \mathrm{mCA})$ and 4.7 bar (47 mCA), respectively, are those considered to be the lowest and the highest input pressure values at the water supply pipe (in section 1). The pressure drop between the place where the pressure gauge was mounted and section 1 of the supply pipe registered a value of 0.3 bar ( $3 \mathrm{mCA})$. From all these aspects mentioned above, it results a maximum supply pressure of $5.0 \mathrm{bar}(50 \mathrm{mCA})$.

Normally, the pressure of the supply pipe of the looped network should vary between 4.0 and 5.0 bar. But in the case of a leakage, depending on the hole parameters, the awareness, location and the repair time, the pressure can drop significantly, even under the minimum value of 4.0 bar, value imposed by a good functioning of the consumers equipment.

A leakage on the supply pipe implies an important pressure drop on the system, under the value of 4.0 bar. Hence, considering the existence of a leakage on the water supply pipe to validate all data and methodology presented before, the service pressure is considered to drop from 3.9 (39 mCA) to 3.0 bar (30 mCA) (values encountered in table 4 , too).

All these hypotheses have been made for the validation of the influence that the pressure drop has upon the water flow. Practically, the water loss decreases directly proportional with the supply pressure $\mathrm{p}_{1}$. For water loss reduction it is extremely important to have smallest supply pressure, but not to small to affect the consumers' pressure. This pressure control can be realized with the help of the pressure management method whose major benefit is to reduce leakage rate by controlling the service pressure on the supply pipe and on the looped network (Laneuville, 2015).
Three scenarios for a leakage on the supply pipe are further presented to validate the above hypotheses in the following circumstances:

a) the leakage will appear when the pressure meets its maximum value, between 3 and 4 am time when water flow is minimum;

b) the "repair" time of the leakage will be around 5 to 24 hours;

c) the hole diameter on the supply pipe wall is between 2-24 mm.

Water losses have been determined and then presented for each scenario. The values of the water losses obtained are indicated on the ordinate of the graphic, in $\mathrm{m}^{3}$.

\section{Scenario 1:}

Supply pipe pressure is $50 \mathrm{mCA}$ and drops to a final pressure $\mathrm{p}_{\mathrm{h}}$ of $39 \mathrm{mCA}$ because of the appearance of a leakage in the system.

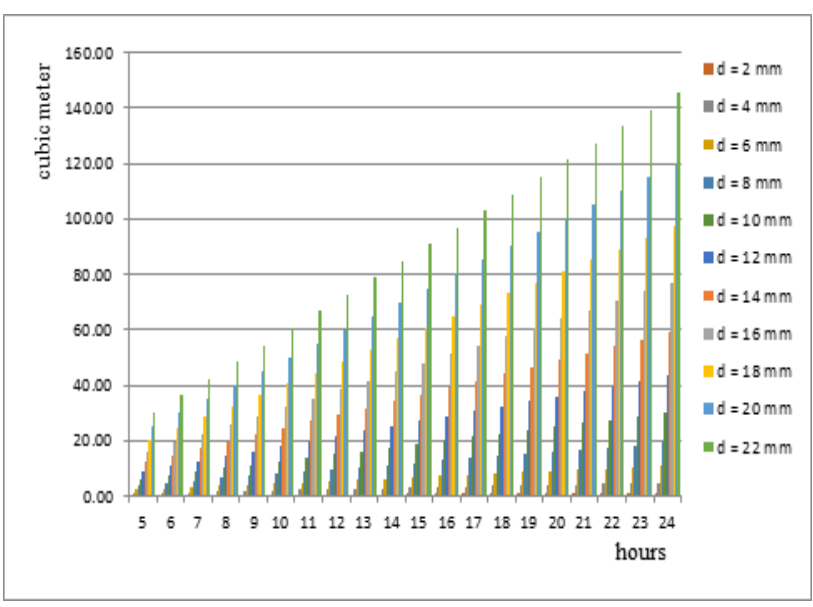

Figure 3. Water losses according to the repair time and hole diameter on the supply pipe wall for $\mathrm{p}_{1}=50 \mathrm{mCA}, \mathrm{p}_{\mathrm{h}}=39 \mathrm{mCA}$

Scenario 2:

Supply pipe pressure is $45 \mathrm{mCA}$ and drops to $39 \mathrm{mCA}$. 


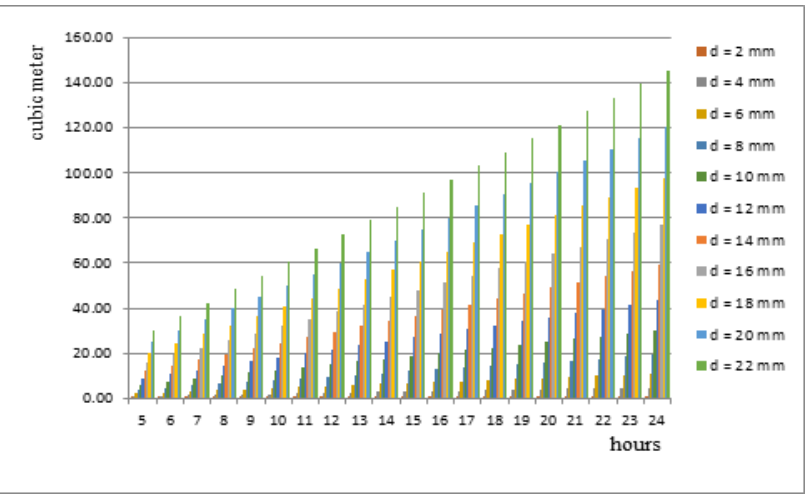

Figure 4. Water losses according to the repair time and hole diameter on the supply pipe wall for $\mathrm{p}_{1}=45 \mathrm{mCA}, \mathrm{p}_{\mathrm{h}}=39 \mathrm{mCA}$

Scenario 3:

Supply pipe pressure is $40 \mathrm{mCA}$ and drops to $39 \mathrm{mCA}$.

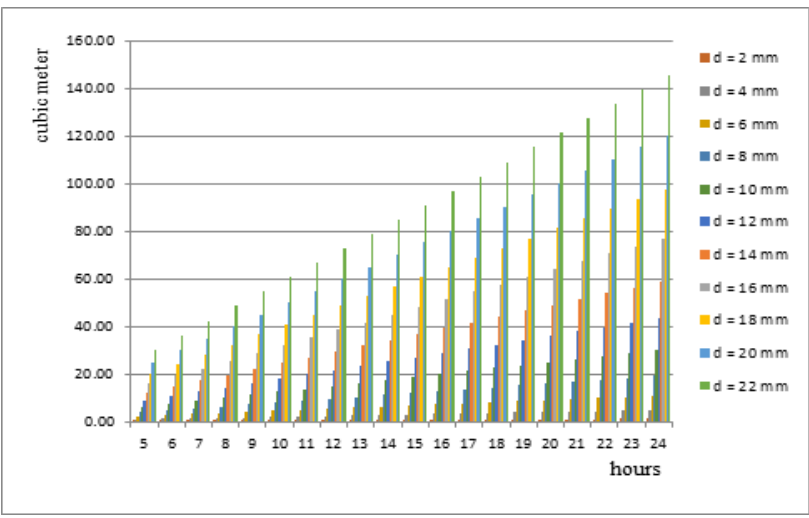

Figure 5. Water losses according to the repair time and hole diameter on the supply pipe wall for $\mathrm{p}_{1}=40 \mathrm{mCA}, \mathrm{p}_{\mathrm{h}}=39 \mathrm{mCA}$

\section{RESULTS AND DISCUSSION}

Subsection 2.3 - the linear friction losses along the supply pipe - together with the values calculated according to the corresponding equations and then presented in tables 2 and 3 , indicates that for a constant supply pressure $\mathrm{p}_{1}$, for a straight and horizontal supply pipe, the pressure can be considered almost constant along the pipe. This aspect is confirmed by the extreme small variation of the pressure of the supply pipe during an entire day. When maximum water flow is considered for the calculation of the hydraulic parameters of the supply pipe of the looped network, the pressure drops from $47 \mathrm{mCA}$ (4.7 bar) in section 1 to a minimum of $46.9411 \mathrm{mCA}$ (4.694 bar) in section 2 where the looped network junction is; that means a decrease of $0.2 \%$ extremely insignificant in this situation. The pattern is identically in the case of the minimum flow. From $47 \mathrm{mCA}$ ( $4.7 \mathrm{bar}$ ) in section 1 at the beginning of the supply pipe, pressure drops to a minimum value of $46.97136 \mathrm{mCA}$ (4.697236 bar) in the junction section - a decrease with $0.06 \%$.

No matter what type of water flow is considered - minimum or maximum - nor the year - 2016 or 2017 - tables 2 and 3 emphasis the indirect proportionality between the final pressure $\mathrm{p}_{2}$ in the junction section of the supply pipe with the distribution looped network and all the analysed hydraulic parameters - velocity, Reynolds criteria, Darcy friction factor. The maximum pressure $\mathrm{p}_{2}$ corresponds to the minimum values of the hydraulic parameters, while the minimum pressure (with red colour) coincide with the maximum values of the analysed parameters (blue coloured).

Overall, as discussed so far in this paper, the pressure drop in the supply pipe is influenced by the water flow, water consumption and water losses (real losses) in the case of a leakage on the water supply pipe or on the looped network.

Table 4 from subsection 2.4 shows the impact that the leakage has it upon the supply pressure and water flows. The biggest the hole diameter on the supply pipe wall and supply pressure are, the biggest is the water loss during the leakage on the distribution system. Water real losses are significantly dependent on the supply pressure.

Another important factor that cannot be omitted is the "repair" time; it can last from 5 to 24 hours. All the three scenarios previously presented shows that the real water loss grows once with the "repair" time. To highlight this aspect, table 5 summarizes the water losses registered on the supply pipe in the first 5 hours of leakage, for different hole diameters.

Table 5. Water losses in $\left[\mathrm{m}^{3} / \mathrm{h}\right]$

\begin{tabular}{|c||c|c|c|}
\hline $\begin{array}{c}\mathrm{d} \\
{[\mathrm{mm}]}\end{array}$ & $\begin{array}{c}\mathrm{p}_{1}=50 \mathrm{mCA} \\
\mathrm{p}_{\mathrm{h}}=39 \mathrm{mCA}\end{array}$ & $\begin{array}{c}\mathrm{p}_{1}=45 \mathrm{mCA} \\
\mathrm{p}_{\mathrm{h}}=39 \mathrm{mCA}\end{array}$ & $\begin{array}{c}\mathrm{p}_{1}=40 \mathrm{mCA} \\
\mathrm{p}_{\mathrm{h}}=39 \mathrm{mCA}\end{array}$ \\
\hline \hline 2 & 0.83 & 0.61 & 0.25 \\
\hline 10 & 20.76 & 15.33 & 6.26 \\
\hline 20 & 83.03 & 61.32 & 25.04 \\
\hline
\end{tabular}

Data from table 5 indicates a directly proportional decrease of the water loss with the supply pressure.

Of course, in practice, the pressure is not constant during a leakage and it depends on the supply pressure and the dimension of the leakage (hole diameter). The difference $\mathrm{P}-\mathrm{P}_{\mathrm{h}}$ will be smaller for reduced values of the supply pressure comparing to high values of the supply pressure.

The main goal is to reduce the water loss during a leakage. A solution is to turn to the minimum pressure criteria MPC. This assumes to decrease the supply pressure during the night to the minimum night flow value MNF, but with attention to the minimum supply pressure that cannot be under 4.0 bar (40 mCA), the minimum request by the consumers.

The reduction of the supply pressure during night can be solved in a easy way by starting to implement the pressure management method; in other words, by deployment in the system of a pressure reducing valve PRV after the water flowmeter.

Therefore, a pressure reducing valve is recommended to be added in the network together with an automation and control system able to adjust the pressure according to the water flow, both giving the consumers' needed pressure in the potable water distribution looped network and avoiding the appearance of leakages. A scheme for managing the supply pressure in the network is proposed by the authors in figure 6 . 


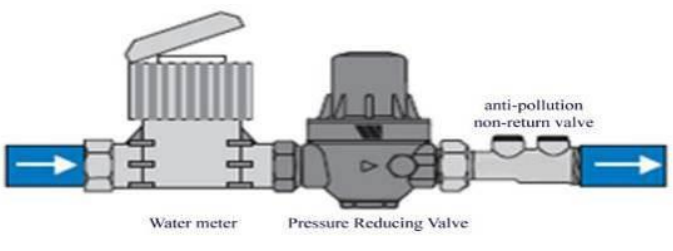

Figure 6. Scheme proposed for managing the supply pressure

After mounting the PRV, a progressive decrease of the supply pressure is assessed along with consumers' pressure monitoring; thus, the optimum supply pressure in ratio with water flow will be determined for a better service of the potable water distribution looped network.

\section{CONCLUSIONS}

Water losses depends on the supply pressure of the potable water distribution looped network and because of this reason, pressure management represents a viable solution with positive impact on the reduction of the real water losses that are part of the NRW (as it results from figures 3, 4, 5 and table 5). In the same time, the pressure management method is a safety measure to prevent the overpressure in the system.

The decrease of the supply pressure to the consumers' minimum value will also have a positive impact over the entire potable water distribution looped network.

In conclusion, pressure management is one of the fundamentals of a good and well-organized management and monitoring of the potable water distribution networks to reduce the NonRevenue Water percentage as regards water real losses. Multiple advantages results:

- Decrease of water loss;

- Better reliability;

- Continuous water supply and reduction of leakages on the distribution looped network;

- Reduction of the pressure fluctuations that leads to a more balanced pressure service on the entire system;

- Extension of pipes and equipment's life.

\section{References:}

De Paola, F. and Giugni, M., 2012. Leakages and pressure relation: an experimental research, Drinking Water Engineering and Science, 5, pp 59-65.

Gomes, R., Marques, A. S., Sousa, J., 2011. Estimation of the benefits yielded by pressure management in water distribution systems.Urban Water Journal; 8(2), pp 65-77.

Gomes, R., Sousa, J. and Marques, A. S., 2013. The influence of pressure/leakage relationships from existing leaks in the benefits yielded by pressure management, Water Utility Journal 5, pp 25-32.

Karadirek, I. E. \& Kara, S. \& Yilmaz, G. \&Muhammetoglu, A. \& Muhammetoglu, H., 2012. Implementation of Hydraulic Modelling for Water-Loss Reduction Through Pressure Management, Water Resources Management 26(9), pp 25552568 .
Laneuville, M., 2015. Gestion de la pression d'eau dans les reseaux de distribution pour une utilisation durable de l'eau et des infrastructures, Vecteur Environment, pp. 44-50.

Mckenzie, R., Seago, C., 2005. Assessment of real losses in potable water distribution systems: some recent Developments, Water Science Technology Water Supply 5(1), pp 33-40.

Nourhan, S., Rawya, K., Walid, E., Amr, F., 2017. Pressure control for minimizing leakage in water distribution systems, Alexandria Engineering Journal, pp 601-612.

Salmasi, F.,*, Khatibi, R., Ghorbani, M. A.,2012. A study of friction factor formulation in pipes using artificial intelligence techniques and explicit equations, Turkish Journal of Engineering and Environmental Sciences 36, pp. 121 - 138.

Tabesh, M., Asadiyani Yekta, A. H., Burrows, R., 2009. An Integrated Model to Evaluate Losses in Water Distribution Systems, Water Resource Management 23, pp 477-492.

Thornton, J., Lambert, A., 2005. Progress in practical prediction of pressure: leakage, pressure: burst frequency and pressure: consumption relationships, Proceedings of IWA Special Conference 'Leakage 2005', Halifax, Nova Scotia, Canada, September, pp 12-14.

van Zyl, J. E., 2014. Theoretical Modeling of Pressure and Leakage in Water Distribution Systems, 16th Conference on Water Distribution System Analysis, WDSA 2014, Procedia Engineering 89, pp 273 - 277.

Farley, M. and Trow, S., 2003. Losses in water distribution networks. A practitioners guide to assessment, monitoring and control, IWA Publishing, UK, pp. 6-8

Marian, L., Muste, M., 1993. Hidraulică şi maşini hidraulice,volumul I, (Hydraulics and Hydraulic Machines, volume I). Cluj-Napoca. Ed. Lito Institutul Politehnic, pp 276284.

Georgescu A. M., Georgescu S. C., 2007. Hidraulica reţelelor de conducte şi maşini hidraulice (Hydraulics of pipeline networks and Hydraulic Machines), Editura Printech, pp 60-62.

Lambert, A., 2000. What do we know about pressure-leakage relationships in distribution systems in System Approach to Leakage Control and Water Distribution Systems Management, Specialized Conference Proceedings, IWA, Brno

Lambert, A., Fantozzi, M., Shepherd, M., 2017. FAVAD Pressure \& Leakage: How Does Pressure Influence N1, IWA Water Efficient Conference.

***Control and mitigation of drinking water losses in distribution systems, EPA 816-R-10-019, November 2010.

*** NP 133-2013, 2013. Normativ privind proiectarea, executia si exploatarea sistemelor de alimentare cu apă si canalizare a localităţilor (Norms regarding the design, execution and functioning of municipal water and sewerage systems), vol. 1. Bucureşti. Ed. MATRIX ROM, pp 173-178. 